\title{
16 \\ Involving Older Gay Men in Research: The Lure of Group Experience
}

\author{
Kip Jones and Lee-Ann Fenge
}

\section{Introduction}

This chapter considers ways to involve older gay men in research, reflecting upon the experience gained through two projects involving older gay men in group experiences. In both projects, male participants were keen to become involved in opportunities to meet and cooperate as groups, and relished the opportunity to come together to share their experiences. This chapter will explore why tools such as participatory action research and focus groups are appealing to older gay men as methods for sharing their experiences. It will consider how older gay men make use of the group experience, and the benefit this brings to an overall research project.

\section{Background}

When considering why and how older gay men become involved in research projects, it is important to contextualize their lives within wider historical and social contexts (Clunis et al., 2005). Life events and societal approaches towards homosexuality will have sculpted both individual and group identity. Many grew up when homosexuality was still illegal and criminalized, and as a consequence they may have masked their sexual orientation, and lived in fear of homophobia (Fredriksen-Goldsen and Muraco, 2010). For older gay men, identity is not only influenced by their sexual orientation, but also mediated by a myriad of other social locations. As a result, they may be silenced by multiple levels of discrimination including ageism, heterosexism and homophobia (LeCompte, 1993), and hidden identities may result in higher levels of personal, social and geographic isolation (McCarthy, 2000; Boulden, 2001; D'Augelli and Grossman, 2001; Beard and Hissam, 2002; Fenge and Jones, 2011;). Normative notions of masculinity are strongly tied 


\section{Involving Older Gay Men in Research}

\section{PROOF}

to youth and to heterosexuality (Slevin, 2008), therefore ageing may pose particular challenges for older gay men.

A key feature of the current ageing population of gay men is their shared history of HIV/AIDS as it developed in the 1980s and the impact this had in 'decimating social networks and shaping their personal and social lives' (Rosenfield et al., 2012, p. 255). Coming together in a group with other older gay men may therefore offer opportunities for validating a 'lived' experience of loss, discrimination and stigma, and such connections can offer resilience to both individual and group identity. Research with sexual minority youth suggests group experience may 'acknowledge a group's collective experience of discrimination' (Di Fulvio, 2011, p. 1616), and this may also be true for older gay men who have a collective history of prejudice and discrimination to share.

The experience of stigma and prejudice across the life course can increase the experience of isolation and stress levels for older gay men (Meyer, 2003; Iwasaki and Ristock, 2007). The complexity of the interrelationships between biographical diversity and social context (Cronin and King, 2010), allows us to consider the myriad of factors that influence identity and social connectedness. Some may be 'out' and integrated into a gay lifestyle, while others may be 'closeted' and isolated from the support of a wider gay community. Enabling older gay men to share and voice their experiences through groups enables researchers to develop a deeper understanding of the effects of personality, personal history, health, gender, sexuality, support networks, marital status and ethnic and cultural differences on ageing and sexuality.

\section{Sharing in a group context}

Many older gay men have negotiated their identity within a heteronormative, family-based society. As non-heterosexuals, gay men have lived outside of the traditional supports for identity and relationships (Weeks et al., 2001), and have needed to find support and connections within their own community or family of choice. Social connectedness is important to the experience of individual well-being and has been demonstrated to be beneficial in times of stress (Cohen, 2004), and fellowship groups for older gay men in the United States have been described as 'affective fellowship', providing social support to often isolated individuals (Shokeid, 2001).

Social dimensions of well-being include a sense of belonging, and can be linked to notions of social capital and social contacts that give support (Gray, 2008). Providing opportunities for older gay men to share their experiences through a research or community group offers opportunities for individuals to pool their social capital and develop resilience through connectivity with others. Equally important is the opportunity to come together as a community of storytellers. Focus groups offer situations in which personal narratives 


\section{PROOF}

Kip Jones and Lee-Ann Fenge 211

are intertwined with identities and communities (Plummer, 1995), and can be an important tool as the discursive nature of the focus group allows older gay men to validate their narratives as well as explore new networking possibilities.

Being part of a group, be it an informal support group or a research focus group, brings individuals together for a common purpose. Focus groups can encourage discussion around 'sensitive' issues, and have been used to explore end of life experiences of older LGB (Lesbian, Gay and Bisexual) people and bereavement within same sex relationships (Almack et al., 2010), and the nature of stress for lesbians and gay men (Iwasaki and Ristock, 2007). Focus groups offer the opportunity to share narratives and engage in interpretative practices through which social realities are constructed. For gay men, this may involve negotiating the socially constructed negative view of homosexuality, and the influence this has had on their identity across their life course.

The following sections will explore the involvement of older gay men in two research projects. The first embraced a participatory action research methodology to work with a group of older lesbians and gay men for three years to explore their experiences of ageing (Gay and Grey Project, 2006; Fenge, 2010). The second (Fenge et al., 2010; Fenge and Jones, 2011) built on the themes emerging from the first project, and focused on how 'coming out' narratives are used as a way of negotiating identity over the life course.

\section{The Gay and Grey Project}

The Gay and Grey project was a joint initiative between a voluntary agency working with older people in Dorset, and Bournemouth University, funded for three years by the Big Lottery Fund. The project was among the very first in the United Kingdom to undertake participative action research (PAR) with older lesbians and gay men. PAR has been used effectively with other groups of marginalized people to support social justice and to promote the voices of these groups (Cahill, 2007; Etowa et al., 2007), and it was therefore felt to be an appropriate method when working with older LGB people who may have experienced lifelong discrimination. PAR was used to support and facilitate older lesbians and gay men's engagement in research about their experiences of social exclusion and marginalization.

A core group of up to 20 volunteers was involved in the project, and they were self-identified non-heterosexuals, aged between 55 and 85 years. The project aimed to

(1) Identify factors and issues that may contribute to older lesbian and gay exclusion from the wider community, the gay community itself and from the support, services and activities available, and

(2) Identify how these issues could be addressed. 


\section{Involving Older Gay Men in Research}

Using a PAR approach is not straightforward, and different group members bring disparate and sometimes competing aspirations for the project to the table. A major challenge was to engage with people drawn to the project for different reasons. As Bradbury and Reason (2001, pp. 449-450) suggest, 'different individual members are likely to hold different questions with different degrees of interest'.

This provided a challenge to both researchers and to the older volunteers, as they needed to recognize 'otherness' and value the contributions of others within the research process. Group processes can lead to 'political disempowerment' (Lennie, 2005), a situation in which certain participants take control of a project thereby excluding 'other' voices and ideas. This can result in some people being silenced by a project that sets out to empower them. Participatory action research therefore has the capacity to be 'exclusive' as well as 'inclusive' (Fenge, 2010).

Coming together as a mixed group in a participatory action research project allowed both older lesbian and gay men to share 'collective' experiences associated with their sexuality. This meant confronting assumptions that both men and women had about each other's experiences. One older lesbian volunteer describes this process of coming together as a mixed group:

There was some kind of assumption that men's and women's issues were different. This turned out to be wrong actually; there was a difference certainly... but the fears, needs, aspirations and expectations were very much the same - and we fairly quickly re-thought the idea of separatism and re-grouped.

(Fenge et al., 2009, p. 517)

This highlights the importance of allowing participants to define group membership and participation. As is the case in any group coming together for the first time, the group evolved as the focus of the research emerged and became embedded. Interestingly, the appeal of the project appeared to divide along gendered lines. The older lesbians were keen to become involved in the research process itself, engaging in both the quantitative and qualitative aspects of the research project. They readily took on the role of researcher, undertaking research and analysing data, and later becoming involved in writing a text book and several academic papers.

In contrast, the older gay men appeared to be motivated by a desire to meet others through groups and networks (Fenge et al., 2009). Therefore, the social aspect of the project, and the opportunity it afforded to meet in a relatively safe environment, was a central preoccupation. This is described by one male volunteer who reflected on his experience of the project:

From the very beginning of the project it became apparent that there was a great need for some way of helping older gay men in the outlying areas of the county get in touch with and socially interact with their 


\section{PROOF}

Kip Jones and Lee-Ann Fenge 213

peers.... Some of these men were very disappointed when they learned that it was not, strictly speaking, within the remit of the project and there was a fair amount of drop-out among the male volunteers as a result.

(Fenge et al., 2009, p. 156)

Those volunteers that remained with the project readily took on 'outreach' roles and raised the profile of the project with agencies across health- and social-care sectors. Some volunteers also spent a considerable amount of effort trying to set up a social structure for those men who wanted to share their experiences with other gay men in a group. As a result, some facilitated small groups were set up in more rurally isolated parts of the local area, and through these meetings the volunteers tried to encourage members to take ownership and responsibility for organizing events among themselves. These smaller groups provided a safe haven for older gay men to share their collective experiences within a supportive environment. This aspect may be particularly important for gay men who are ageing with stigma attached to both old age and homosexuality (Slevin, 2008).

What became evident through the project was that multiple forms of masculinity and identity exist and these are produced by the intersections of various factors including class, ethnicity, age, sexuality and location. Older gay men can be both 'advantaged and disadvantaged by these interlocking systems of power and oppression' (Slevin and Linnemann, 2010, p. 484). Some men who were attracted to the project were 'out' and happy to share this with other people as part of the roles they took during the project. Others wanted to remain hidden, after living a lifetime with fear and stigma, and were looking for a 'safe' group to join. To a certain extent, the project offered a place for these different needs to be met. Through the 'social' group, older gay men were able to meet on a regular basis for support, and through a range of activities those wanting to change policy and practice became involved in research and practice development.

The project seemed to attract individuals who wanted a 'group' experience where they could share a feeling of solidarity with each other, and validate their identities and masculinities as older gay men through a shared history and understanding. Such natural groups or social networks appeared to be missing from their lives, and some volunteers readily joined the project in the hope that it would fill this void. It was disappointing that, despite a good deal of effort from the volunteers in terms of establishing 'social' groups for isolated older gay men, the groups were not self-sustaining, and soon ended when the project itself concluded.

\section{Gay and Pleasant Land? - A study about positioning, ageing and gay life in rural south-west England and Wales}

The Gay and Pleasant Land? project began with two points of interest resulting from the Gay and Grey project: first, 'coming out' stories seemed to be a 


\section{Involving Older Gay Men in Research}

pervasive coping device used by participants in the study; and second, little was known about older gay lives and experiences of those gay citizens who may be geographically isolated in rural settings.

Through an exploration of the recollections, perceptions and storied biographies of older lesbians and gay men and their rural experiences, the Gay and Pleasant Land? project focused on connectivity and the intersections between place, space, age and identity, and the life course that describes those past connections. As part of the overarching Grey and Pleasant Land? group of studies on ageing in rural south-west England and Wales under the national UK research programme, New Dynamics of Ageing, 'connectivity' was a central concept in developing an understanding of how sense of belonging may be negotiated within a rural context. The umbrella Grey and Pleasant Land? project investigated the key ways in which older people are connected to their rural communities; that is, culturally, socially, economically and technologically, and, through these, examined older people's involvement in civic life. 'Connectivity' can be understood vis-à-vis the Gay and Pleasant Land? project as the ways in which individuals identify and connect themselves with others and the ways in which this may be filtered by aspects of their age and sexuality. Identity and the ways in which older gay men chose to disclose their sexuality as part of their identity exerts an influence on the particular ways in which these individuals made such connections. Biography was seen as a retrospective way in which to explore the lifespan and the way in which memory constructs and influences present-day connectivity.

The emerging recollections, perceptions and storied biographies of older gay citizens and their rural experiences formed the bulk of the data gathered and the basis for story and characterization of a short professionally made film, Rufus Stone (2012), the main output of the project. Although older lesbians were equally included in the study, it was the stories told by older gay men, individually and in groups, which mainly informed the Project Team in the creation of the story for the film, using composite characters as a literary device, or a 'fictive' reality (Jones, 2012b). Fictive reality is conceived as the ability to engage in imaginative and creative invention while remaining true to the remembered realities as told by participants in a study. A similar incident or report may be told by several participants through the research process. When these reports are combined into one person's story, a 'fiction' is born. Second, when writing the script, the characters 'take over', another device of fiction writing. At all times during the writing of the story and script for the film, however, shuttling back and forth to the raw interview data was key.

The project's main aim was to empower both older lesbians and gay men in rural areas through a collaborative multi-method participatory action research design, which embraced the principles of a Performative Social Science (Jones, 2006) in its dissemination plan. The film was made in order to 


\section{PROOF}

Kip Jones and Lee-Ann Fenge 215

encourage community dialogue and inform service providers, to 'open up (one or two) obstructed passages, and to connect levels of reality kept apart from one another' (Bourriaud, 2002, p. 8).

\section{Methods}

A range of methods was used to generate the storied biographies of older gay citizens about their rural experiences. These included in-depth biographic life story interviews (BNIM) (Jones, 2001, 2004a) and actual site visits to the rural locations where older gay citizens were living. Sifting through the initial raw data from the interviews, certain questions remained unanswered; others begged to be fleshed out. Some crucial points were raised in the interviews, but not elaborated upon by the participants. It was decided to organize a focus group or 'coffee morning' in order to focus more specifically on these remaining questions and expand upon the richness of the individual interviews. What had become clear from our biographic interviews was that it was not so important that participants currently resided in the countryside, but rather, that they had experience of rural living at some point over the life course. Migration had been a typical occurrence in the life stories for all but one of the individuals we interviewed. We also opened the focus group up to younger (50+) participants who were gay and had experience of rural living.

The national UK Gay News picked up the story and publicized the coffee morning, creating wider interest in participation. Except for one lesbian who was already coming for an individual interview at the time, the focus group ended up consisting of men, probably due to the Gay News' circulation. The discussions were lively and informative, bringing personal experiences and details to the mix of queries, which proved helpful to the development of the story for the film. What impressed the organizers most, however, was how this opportunity for (mostly) men to gather, 'tell tales' and converse, seemed really important to them - a unique and valued experience. At the end of the morning, it was as though they did not want this seemingly rare opportunity for informal interaction to end. In every case, from the initial in-depth interviews, to the site visits and finally in the focus group, these gay men seemed particularly willing - even proud - to be contributing to our study. Involvement in the project was perceived as giving the tales from their life stories a sense of legitimacy - stories that often have been kept hidden from or silent in their local, often rural, communities. Open-ended probes focused, nonetheless, on particular areas where stories, which we had heard needed to be fleshed out:

- What is/was it like being gay and living in the countryside?

- How do you/did you cope with being gay and living in a small community? 
216 Involving Older Gay Men in Research

- How open are you/were you about being gay to neighbours and other people in the village?

- How do people treat you differently because you are gay or when they suspect that you are different?

- How do services (doctors, nurses, social services and so on) treat you differently?

- How do you/did you maintain friendships with other gay people in the countryside?

- What is the worst thing that has ever happened to you because you are gay? What is the best thing?

- How has growing older made a difference in the place that you live? Or how has the place that you live made a difference in growing older?

\section{Coffee Morning focus group probes}

Guy, a taxi driver in his late 50s, was the youngest participant in the focus group, and it was interesting to note that his stories were eagerly listened to by the other older participants. Perhaps Guy's tales represented possible alternative concepts of masculinity not perceived as available to the older generation of gay men? When he spoke at the Coffee Morning about his interactions through his job, Guy's presentation and style seemed to indicate to the group that things, indeed, were changing:

I'm a taxi driver um, in D ..., which is a pretty 'butch' job, had to take the jewelry off and stop the make-up...

*group laughter*

But I, um, but I was a taxi driver for 13 years and I thought perhaps I can do a little bit of good here, um, perhaps I can, um, perhaps if I say who I am, um, people can see I'm, I don't I'm not particularly camp, not the stereotypical gay man, and if people can see that gay people are just ordinary and then perhaps I'm doing a little bit of good, and as it turned out I was able to... and it became Guy the gay taxi driver rather than Guy the nice taxi man.... I was also the catalyst for other gay men um unfortunately as a taxi driver working at night you get propositioned um and I had um young lads proposition me... very flattering ... um um because they thought this was the only way to make contact with someone that was gay...just to simply chat to these guys from the villages just to say 'look you know um you don't have to sort of you know offer yourself to someone um just to have a chat with them um let's have a chat let's talk about things' .... There was a regular lad who I used to pick up went to G... um and er we got talking and he was able to sort himself 


\section{PROOF}

Kip Jones and Lee-Ann Fenge 217

out mentally through talking. Unfortunately pressure was on him and he eventually stayed in the straight world.'

Following the interviews and citizen panel analyses of the data (see Jones, 2001, 2004a) and the subsequent focus group, conversations (rather than formal meetings) were carried out by the project's researchers and its advisory committee consisting of active older gay citizens and representatives of service providers. The researchers and volunteers sifted over the materials and stories, suggesting possible plot lines, turns and twists, and contributed to the development of the main characters - always constantly shuttling back and forth to and from the research data itself.

Eventually, a dramatic arc began to emerge for the film's story and its inhabitants. At this stage, the project director began writing Rufus Stone (2012) as a story on his weblog (Jones, 2012c). This resulted in the 'treatment' for the film that was then handed over to the film's director who wrote the final script, always in consultation with the Project Director to ensure accuracy with the research findings and to maintain the purpose intended from the outset of the Project.

The project lead and author of the story for the film, Kip Jones, reflects:

How much of the story of Rufus Stone is my story? This is a difficult question. As an older gay man, of course I identify with the characters. Nonetheless, I grew up in a different country in a different time and under different circumstances. Still, there are similar memories and these are helpful in writing the background for the film. It also makes it easier for me to say to the director, 'No, they wouldn't react that way, rather this way'. There are certain experiences (or perhaps 'memories' to be more exact) that we share in common. In conducting a biographic interview with one of the volunteers, I recall clearly his reaching a point in his story when he was also telling my story. It was quite a moment for me and reinforced a fact that is so often overlooked in reporting on lesbian and gay experiences: accounts are not simply tales of sexual encounters: they are stories about relationships which are often complex ones with histories grounded in family, community, place and time. The final resource then was a trust in my own memories or reliance on auto-ethnography as the final piece of the puzzle in bringing the composite characters to life and enriching the plotline before handing it over to the film's director who created the final script.

This retrospective imagining or 'musing', supported by narrative biographical theory, is extended in this case to the illusory biographies of others and constructed within a sense of other as created by an imaginative projection of self onto their worlds (Jones, 2012a), creating 'dialogue(s) which never 
happened' (Reisz, 2012). In the end, the film renders poetically the way in which our memories morph and play with our histories, much as dappled sunlight reveals, then conceals, an idyllic landscape.

Josh Appignanesi, the film's director, outlines the story of Rufus Stone (2012):

The story dramatizes the old and continued prejudices of village life from three main perspectives. Chiefly it is the story of Rufus, an 'out' older gay man who was exiled from the village as a youth and reluctantly returns from London to sell his dead parents' cottage, where he is forced to confront the faces of his estranged past. Of these, Abigail is the tattle-tale who 'outed' Rufus 50 years ago when he spurned her interest. She has become a lonely deluded lush. Flip, the boy Rufus adored, has also stayed in the village: a life wasted in celibacy (occasionally interrupted by anonymous sexual encounters) and denial [who is] looking after his elderly mother. But Rufus too isn't whole, saddled with an inability to return or forgive.

\section{Key findings}

- Although the laws changed regarding the illegality of homosexuality in 1967, men whose sexual identity developed before that change were profoundly marked by growing up during the period when homosexuality was illegal and punishable by imprisonment.

- Being born in one particular rural location and spending a lifetime, there is extremely rare. It may, in fact, be the case that many who complain of 'incomers' in rural areas were, at one time, incomers themselves.

- Prejudice was reported by gay men, particularly in small rural communities.

- A secondary danger was uncovered in an attitude of 'we don't like to mention it' regarding the sexuality of others among rural dwellers - a rural version of a 'don't ask don't tell' mentality.

- Many older gay and lesbian citizens need to negotiate 'acceptance' in rural areas by being extremely cautious about to whom and when they 'come out', if at all.

- Negotiation with service providers also is often either fraught with difficulties or non-existent in many of the reported cases.

- Stories of suicide among older gay men were prevalent in several of the accounts that participants gave.

\section{Implications for policy, practice and public engagement}

The projected impact of the project's film is to begin to change minds, change attitudes and help to build communities where tolerance and 


\section{PROOF}

Kip Jones and Lee-Ann Fenge 219

understanding are keys to connectivity and to increasing the value of the social capital of all citizenry in rural settings.

Problems of isolation, lack of mobility, limited friendship and support networks, along with issues of lack of service provision, are all discussed among older gay men in the research much in the same way that they are concerns for the larger heterosexual ageing population.

Whether real or imagined, class is also a major component in many of the stories reported. Class and perceptions of class are issues that emerged repeatedly in the life stories of participants.

\section{Further outputs}

The film, Rufus Stone (2012), continues to be screened at both academic and civic gatherings, with the expectation of wider viewing by the public in the near future through television, film festivals and general distribution. Early audience responses to screenings of the film as well as further information about the background to the research and the making of the film are available on the Rufus Stone website: http://blogs.bournemouth.ac.uk/ rufus-stone/.

A 'Method Deck' of cards is being produced through a grant from the Big Lottery Fund. This follow-on project will provide a playful tool for use by service providers and community groups to begin to deal with prejudice against and isolation of older gay citizens within community groups and services.

A small study on diversity and bereavement is currently being undertaken at Bournemouth University, which includes interviewing older gay and lesbian citizens and listening to their stories of loss and the complexities that sometimes arise when dealing with loss in a heteronormative culture.

The ESRC Festival of Social Science has funded a one-day event for Autumn, 2012, titled: 'Pathways to impact: Ageing, diversity, connectivity and community', which will bring together service providers, representatives of community and LGBT groups, and academics for a screening of the film and the launch of the Methods to Diversity pack of cards.

\section{Conclusion}

Project Lead, Kip Jones, recalls a moment of hope and the possibility of attitudes changing among younger generations:

A phrase that is well over one hundred years old is often repeated by some members of an older generation that seems incapable at times of even tolerating diversity in their midst. When a Victorian actor showed too much affection for the leading man, actress Mrs. Patrick Campbell replied: 'My dear, I don't care what they do, so long as they don't do it in the street 
and frighten the horses'. The fact that a Victorian attitude frozen in time is today seen as an 'amusing' response to an 'uncomfortable' situation simply boggles the mind. 'Traditional values' such as tolerance and fair play seem to have no place in this version of community standards.

The line 'We don't care what you do as long as you don't do it in the road and frighten the horses' is included in the script of Rufus Stone (2012). It is delivered in a speech excusing village attitudes, even making light of a plea for compassion. In the next scene, the lead character discovers that his boyhood friend has just hanged himself. The point of this juxtaposition in the storyline is to emphasize that what we say often does have consequences, often serious ones.

Now for some good news. Between takes of the scene described above, I was waiting with some of the young crew, sheltering ourselves from a sudden shower behind a van packed with leads and sundry cinematic equipment. The boom operator, Dan, fresh from film school with an unbridled enthusiasm for his role, facetiously quizzed me: 'So Kip. Are horses afraid of gay people?'

We all laughed.

'It is less painful to learn in youth than to be ignorant in age' - Proverb.

\section{References}

Almack, K., J. Seymour and G. Bellamy (2010) 'Exploring the Impact of Sexual Orientation on Experiences and Concerns about End of Life Care and on Bereavement for Lesbian, Gay and Bisexual Older People', Sociology, 44, 908-924.

Beard, K.W. and A. Hissam (2002) 'The Use of Erikson's Developmental Theory with Gay Men from Rural Communities', Journal of Rural Community Psychology, E5, 1-13.

Boulden, W. (2001) 'Gay Men Living in a Rural Environment', Journal of Gay and Lesbian Social Services, 12, 63-75.

Bradbury, H. and P. Reason (2001) 'Conclusion: Broadening the Bandwidth of

Validity - Issues and Choice-points for Improving the Quality of Action Research' in P. Reason and H. Bradbury (eds) Handbook of Action Research (London: Sage).

Bourriaud, N. (2002) Relational Aesthetics (trans. by Simon Pleasance and Fronza Woods) (Dijon, France: Les Presses du Reel).

Cahill, C. (2007) 'Including Excluded Perspectives in Participatory Action Research', Design Studies, 28, 325-340.

Clunis, M.K., I. Freriksen-Goldsen, P. Freeman and N. Nystrom (2005) Looking Back, Looking Forward: Lives of Lesbian Elders (Binghamton, NY: Haworth).

Cohen, S. (2004) 'Social Relationships and Health', American Psychologist, 59, 676-684.

Cronin, A. and A. King (2010) 'Power, Inequality and Identification: Exploring Diversity and Intersectionality amongst Older LGB Adults', Sociology, 44, 876-891.

D'Augelli, A.R. and A.H. Grossman (2001) 'Disclosure of Sexual Orientation, Victimization, and Mental Health Among Lesbian, Gay and Bisexual Older Adults', Journal of Interpersonal Violence, 16, 1008-1027. 


\section{PROOF}

Kip Jones and Lee-Ann Fenge 221

Di Fulvio, G.T. (2011) 'Sexual Minority Youth, Social Connection and Resilience: From Personal Struggle to Collective Identity', Social Science \& Medicine, 72, $1611-1617$.

Etowa, J.B., W.T. Bernard, B. Oyinsan and B. Clow (2007) 'Participatory Action Research (PAR): An Approach for Improving Black Women's Health in Rural and Remote Communities', Journal of Transcultural Nursing, 18, 349-357.

Fenge, L. (2010) 'Striving towards Inclusive Research: An Example of Participatory Action Research with Older Lesbians and Gay Men', British Journal of Social Work, 40, 878-894.

Fenge, L. and K. Jones (2011) 'Gay and Pleasant Land? Exploring Sexuality, Ageing and Rurality in a Multi-Method Performative Project', British Journal of Social Work, Advance Access published 4 May 2011, doi:10.1093/bjsw/bcr058.

Fenge, L., A. Fannin, A. Armstrong, T. Hicks and V. Taylor (2009) 'Lifting the Lid on Sexuality and Ageing: The Experiences of Volunteer Researchers', Qualitative Social Work, 8, 509-524.

Fenge, L., K. Jones and R. Read (2010) 'Connecting Participatory Methods in a Study of Older Lesbian and Gay Citizens in Rural Areas', International Journal of Qualitative Methods, 9, 320-333.

Fredriksen-Goldsen, K.I. and A. Muraco (2010) 'Aging and Sexual Orientation: A 25Year Review of the Literature', Research on Aging, 32, 372-413.

Gay and Grey Project (2006) 'Gay and Grey in Dorset: Lifting the Lid on Sexuality and Ageing', research report (Bournemouth, Dorset: Help and Care Development Ltd).

Gray, A. (2008) 'The Social Capital of Older People', Ageing and Society, 29, 5-31.

Iwasaki, Y. and J.L. Ristock (2007) 'The Nature of Stress Experienced by Lesbians and Gay Men', Anxiety, Stress and Coping, 20, 299-319.

Jones, K. (2001) 'Narratives of Identity and the Informal Care Role', unpublished PhD dissertation, De Montfort University, Leicester.

Jones, K. (2004a) 'Thoroughly Post-modern Mary (A Biographic Narrative Interview with Mary Gergen)', Forum Qualitative Sozialforschung/Forum: Qualitative Social Research, 5, art. 18, date accessed 6 May 2012, http://www.qualitative-research.net/ fqs-texte/3-04/04-3-18-e.htm.

Jones, K. (2004b) 'Minimalist Passive Interviewing Technique and Team Analysis of Narrative Qualitative Data' in F. Rapport (ed.) New Qualitative Methodologies in Health and Social Care (London: Routledge).

Jones, K. (2006) 'A Biographic Researcher in Pursuit of an Aesthetic: The Use of Artsbased (Re)presentations in 'Performative' Dissemination of Life Stories', Qualitative Sociology Review, 2, 66-85.

Jones, K. (2012a) 'On a Train From Morgantown: A Film Script', Psychological Studies, $57,224-235$.

Jones, K. (2012b) 'Short Film as Performative Social Science: The Story Behind Princess Margaret' in P. Vannini (ed.) > Popularizing Research $>$ (Bern: Peter Lang Publishing).

Jones, K. (2012c) KIPWORLD, weblog, http://kipworldblog.blogspot.co.uk/

LeCompte, M.D. (1993) 'A Framework for Hearing Silence: What Does Telling Stories Mean When we are Supposed to be Doing Science?' in D. McLaughlin and W.G. Tierney (eds) Naming Silenced Lives: Personal Narratives and Processes of Educational Change (New York: Routledge).

Lennie, J. (2005) 'An Evaluation Capacity-Building Process for Sustainable Community IT Initiatives', Evaluation, 11, 390-414.

McCarthy, L. (2000) 'Poppies in a Wheat Field: Exploring the Lives of Rural Lesbians', Journal of Homosexuality, 39, 75-94. 
Meyer, I.H. (2003) 'Prejudice, Social Stress, and Mental Health in Lesbian, Gay and Bisexual Populations: Conceptual Issues and Research Evidence', Psychological Bulletin, 129, 674-697.

Plummer, K. (1995) Telling Sexual Stories: Power, Change and Social Worlds (London: Routledge).

Reisz, M. (2012) 'Big-screen Vision Breaks Academic Boundaries', Times Higher Education, 5 January, date accessed 1 August 2012, http://www.timeshighereducation.co. uk/story.asp?storycode $=418561$.

Rosenfield, D., B. Bartlam and R.D. Smith (2012) 'Out of the Closet and Into the Trenches: Gay Male Baby Boomers, Aging and HIV/AIDS', The Gerontologist, 52 , 255-264.

Rufus Stone (2012) Motion Picture, produced by Parkville Pictures, London, directed by Josh Appignanesi.

Shokeid, M. (2001) 'Our Group Has a Life of its Own: An Affective Fellowship of Older Gay Men in New York City', City and Society, 13, 5-30.

Slevin, K.F. (2008) 'Disciplining Bodies: The Aging Experiences of Older Heterosexual and Gay Men', Generations, 32, Spring, 36-42.

Slevin, K.F. and T.J. Linneman (2010) 'Old Gay Men's Bodies and Masculinities', Men and Masculinities, 12, 483-507.

Weeks, J., B. Heaphy, and C. Donovan (2001) Same Sex Intimacies: Families of Choice and Other Life Experiments (London: Routledge). 